\title{
INTERNACIONALIZAÇÃO E LÍNGUAS ADICIONAIS: UMA DESCRIÇÃO DAS POLÍTICAS LINGUÍSTICAS DA UFRGS
}

\author{
INTERNATIONALIZATION AND ADDITIONAL LANGUAGES: \\ A DESCRIPTION OF LANGUAGE POLICIES AT UFRGS
}

\author{
Álvaro Rutkoski Didio ${ }^{1}$, Anamaria Kurtz de Souza Welp ${ }^{2}$
}

\begin{abstract}
RESUMO: As universidades brasileiras têm atentado às demandas linguísticas que emergemno contexto de internacionalização, buscando promover a qualificação da educação superior brasileira no cenário mundial. Nesse contexto, o objetivo deste artigo é analisar o papel das línguas adicionais através das ações voltadas para ou que culminam no processo de internacionalização da Universidade Federal do Rio Grande do Sul (UFRGS),à luz dos conceitos de Internacionalização, Internacionalização em Casa ( $\mathrm{IeC})$ e Políticas Linguísticas. Para tanto, são descritas ações desempenhadas na instituição que de alguma forma contribuem para a sua internacionalização. Como resultado, observamos que a internacionalização da UFRGS é um processo em contínua construção que contribui para a ampliação da participação no debate acadêmico internacional, na qualificação de sua comunidade acadêmica e na visibilidade da produção científica local.
\end{abstract}

$\boldsymbol{P A L A V R A S - C H A V E : ~ I n t e r n a c i o n a l i z a c ̧ a ̃ o ; ~ L i ́ n g u a s ~ A d i c i o n a i s ; ~ P o l i ́ t i c a s ~ L i n g u i ́ s t i c a s ; ~}$ Internacionalização em Casa.

ABSTRACT: Brazilian universities have approached the linguistic demands that emerge in the context of internationalization, seeking to promote the qualification of Brazilian higher education in the world scenario. In this context, the purpose of this article is to analyze the role of additional languages through actions aimed at or culminating in the internationalization process of the Federal University of Rio Grande do Sul (UFRGS), in the light of the concepts of Internationalization, Internationalization at Home and Language Policies. Thus, we describe actions performed in the institution that somehow promote its internationalization. As a result, we note that the internationalization at UFRGS is a process in continuous construction that contributes to the expansion of participation in international academic debates, in the qualification of its academic community and in the visibility of local scientific production.

KEYWORDS: Internationalization; AdditionalLanguages; Language Policies; Internationalizationat Home.

\section{Introdução}

\footnotetext{
${ }^{1}$ Mestrando em estudos da linguagem pela UFRGS.

${ }^{2}$ Doutora em Letras pela PUCRS.
} 
Os debates acerca da internacionalização das instituições de ensino superior (IES) se intensificaram no Brasil especialmente a partir de 2012 com a instituição do programa Ciência sem Fronteiras $(\mathrm{CsF})$, fruto de uma parceira entre o Ministério da Ciência e da Tecnologia e o Ministério da Educação (NICOLAIDES, TILIO, 2013). Naquele cenário, internacionalizar as IES brasileiras foi uma pauta robusta do Brasil, uma vez que o programa proporcionou a universitários brasileiros mais de 100.000 oportunidades de mobilidade. Entretanto, o CsF encerrou suas atividades em 2017, pelo menos no formato em que foi concebido, por não ter alcançado os objetivos esperados ou promovido o devido retorno à

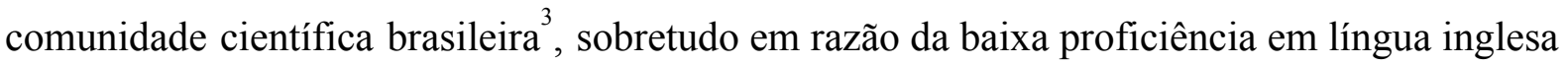
dos alunos. Como consequência, o insucesso do programa levantou questões institucionais e, sobretudo, linguísticas para as IES brasileiras, na medida em que os alunos tiveram grandes dificuldades em interagir e produzir conhecimento com a comunidade científica internacional. Desde então, as IES brasileiras, órgãos e organizações nacionais têm atentado a essas demandas, buscando promover a internacionalização da educação superior no Brasil.

Alguns exemplos desses esforços são, em âmbito nacional e local, o recente edital da CAPES intitulado "Programa Institucional de Internacionalização - PrInt" e o Plano de Desenvolvimento Institucional (PDI) 2016-2026 da Universidade Federal do Rio Grande do Sul (UFRGS). O primeiro, edital aberto a universidades de todo o país, tem por um de seus objetivos "fomentar o desenvolvimento de Planos Estratégicos de Internacionalização como meio de melhorar a qualidade dos cursos de pós-graduação brasileiros e de conferir maior visibilidade à pesquisa científica realizada no Brasil”. Já o segundo, documento local de planejamento institucional, faz um apelo à internacionalização, enquadrando-a como um valor da universidade e buscando promover um caráter mais multilinguístico às ações da universidade, tendo a UFRGS cada vez mais internacionalizada como uma meta a ser atingida.

Nesse enquadramento, podemos perceber como o processo de internacionalização tem se relacionado com as línguas, sobretudo as adicionais ${ }^{4}$. Elas estão presentes nas pessoas,

\footnotetext{
${ }^{3}$ Fonte: Disponível em $<$ http://g1.globo.com/bom-dia-brasil/noticia/2017/04/ciencia-sem-fronteiras-chega-ao-fim-por-falta-de-dinheiro.

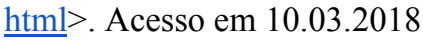

${ }^{4}$ Usamos o termo adicionais, e não estrangeiras, pelo fato de diferentes línguas serem cada vez mais necessárias no cotidiano das pessoas, acrescentando e/ou adicionando a suas vidas. Além disso, estrangeiras pode sugerir uma conotação exótica, diferente ou até indesejada, o que acreditamos não se aplicar a esse contexto (JUDD, TAN, WALBERG, 2001, p.6)
} 
culturas e ideias em constante fluxo entre universidades; nas ações e no currículo; nas exigências de proficiência para participar de programas de mobilidade e no consequente domínio da linguagem acadêmica para produzir conhecimento científico; em editais, buscando visibilidade internacional às pesquisas realizadas; e, por fim, em documentos institucionais que têm a internacionalização como um valor da universidade. Consoante a essa relação, Abreu-e-Lima et al. (2016) colocam que as línguas são o "veículo pelo qual a internacionalização se processa" (p.74), e portanto é natural que haja nas IES ações que envolvam línguas adicionais e que sejam voltadas à internacionalização, ou que nela culminem.

Nesse cenário, é o objetivo deste artigo analisar o papel das línguas adicionais através das ações voltadas para ou que culminam no processo de internalização da Universidade Federal do Rio Grande do Sul (UFRGS)à luz dos conceitos de Internacionalização, Internacionalização em Casa (IeC) e Políticas Linguísticas.

Iniciamos o texto definindo os termos Internacionalização e Internacionalização em Casa e explicando o conceito de Política Linguística. Em seguida, descrevemos as ações que envolvem línguas adicionais voltadas para a internacionalização da UFRGS. Por fim, apresentamos nossa discussão e reflexão buscando explicar tais ações apoiados nos pressupostos teóricos apresentados.

\section{Internacionalização e internacionalização em casa}

Para Knight (2008), a internacionalização pode ser compreendida como a integração de dimensões globais, interculturais e internacionais às funções e aos propósitos da educação terciária. Por ser um meio, e não um fim, para a qualificação do ensino superior, o processo de internacionalização em si se justifica, entre outras razões, pelo desejo ou reconhecimento da necessidade de preparar os alunos universitários para um mundo cada vez mais conectado. Isso significa pretender que eles sejam internacionalmente bem informados e interculturalmente competentes, capazes de viver e trabalhar em comunidades diversas, tanto no país de origem quanto no exterior. Ainda para a mesma autora, outra razão para se internacionalizar as IES é o estabelecimento de uma rede de contatos através da qual se possam compartilhar responsabilidades globais, como a degradação do meio-ambiente, o crescimento populacional, a segurança, o aquecimento global, entre muitos outros. 
Internacionalizar é um processo contínuo que pressupõe lidar com objetivos, estratégias e desafios, que variam muito graças à imensa diversidade das universidades brasileiras (BRITISH COUNCIL, 2018), ingrediente fundamental para se alcançar a excelência na educação superior (DOWLE, 2018).

A internacionalização de uma IES toma forma através de diversas ações e articulações, como, por exemplo, a inclusão de projetos de cooperação e desenvolvimento internacionais, a mobilidade de acadêmicos através de intercâmbios, trabalhos de campo, extensão e trabalhos de consultoria, recrutamento/agenciamento de alunos internacionais, atenção à dimensão internacional/intercultural do processo de ensino/aprendizagem, currículo e pesquisa; entre muitos outros. Existe, no entanto, uma modalidade específica de internacionalização, que se faz relevante para este trabalho: a Internacionalização em Casa (IeC). A IeC se configura através de ações que acontecem no próprio campus e que contribuem para a internacionalização da comunidade acadêmica e da instituição. Elas se pautam em questões de inclusão, diversidade e reciprocidade, uma vez que nem todos os alunos terão a oportunidade de realizar mobilidade acadêmica e de serem expostos a contextos internacionais e culturais in vivo.

Como afirma Teekens (2013) é direito de todos uma educação internacional(izada) de qualidade. Nesse sentido, a $\mathrm{IeC}$ nasce em resposta às iguais necessidades da grande maioria dos alunos, e pode incluir o acolhimento e a integração de alunos estrangeiros às comunidades locais, a promoção do estudo de línguas adicionais necessárias aos propósitos da universidade, a oferta de disciplinas, cursos de graduação e pós-graduação ministrados em línguas adicionais, a ampliação de ofertas de palestras em línguas adicionais, a adaptação dos sites institucionais ao público internacional, o alinhamento das expectativas de aprendizagem para competências e resultados reconhecidos internacionalmente, e assim por diante (BRITISH COUNCIL, 2018).

Com relação aos discursos e práticas locais, reiteramos que a UFRGS tem colocado a internacionalização como pauta de grande importância em seus documentos oficiais, em especial no Plano de Desenvolvimento Institucional (PDI) 2016-2026. O documento aborda o conceito abundantemente e em diferentes seções, colocando a internacionalização como um valor da UFRGS, como relevante para o futuro, como uma política de ensino, pesquisa e extensão a ser ampliada e debatida, e interessantemente como carente de suporte interno. $\mathrm{O}$ PDI ainda discute a necessidade de novas iniciativas de internacionalização, do aumento do 
caráter multilinguístico de ações da universidade, e de aperfeiçoamentos de caráter multilinguístico do corpo docente.

Assim, se antes procuramos deixar clara a relação e a centralidade das línguas adicionais ao processo de internacionalização como um todo, esse vínculo se torna ainda mais basilar no âmbito local, de $\mathrm{IeC}$, em que ações que envolvem línguas adicionais buscam espaço e consolidação no ambiente universitário, seja na sua promoção e ensino, ou em serviços de tradução e testes de proficiência.

\section{Línguas adicionais e políticas linguísticas no processo de internacionalização}

$\mathrm{Na}$ última década, vem-se observando um investimento maior em ações que promovem ensino e testagem de línguas adicionais voltadas para a internacionalização de IESs brasileiras. Programas e iniciativas do governo federal têm evidenciado uma preocupação com a questão da proficiência em línguas tanto sob uma perspectiva global quanto local. Um exemplo desse interesse é o caso do Programa Idiomas sem Fronteiras sobre o qual discorreremos mais adiante neste artigo.

No âmbito da linguística aplicada (LA), Sarmento e Baumvol (2018)investigaram o papel das línguas na internacionalização do ensino superior brasileiro ao analisar os programas das últimas cinco edições da conferência anual da Associação Brasileira de Educação Internacional (FAUBAI) ${ }^{5}$. Motivadas por uma percepção de que a LA estava se fazendo cada vez mais presente nessas conferências, as autoras descobriram que 22 apresentações relacionadas a questões de língua foram feitas em 2017, ao passo que em 2013 haviam sido apenas duas, revelando um crescimento substancial na presença da LA e consequentemente no debate sobre o papel das línguas na FAUBAI.

Nesse enquadramento, quando falamos em ações que envolvem línguas e que promovem ou acabam promovendo a internacionalização da IES, podemos também falar em políticas linguísticas (PL). As PL podem ser entendidas como decisões ou esforços deliberados para que haja determinadas ações que envolvem língua.

\footnotetext{
${ }^{5}$ Desde 1988, a FAUBAI organiza encontros anuais para debater a internacionalização do ensino superior brasileiro. Começando suas atividades com o tímido tema "Os programas de cooperação internacional", a associação chegou a 2018 com: "Internacionalização e Pesquisa: Desafios e Estratégias". Fonte http://faubai.org.br/pt-br/
} 
Para Spolsky (2004), as PL de uma comunidade de fala ${ }^{6}$ podem ser verificadas a partir de três aspectos inter-relacionados: práticas linguísticas, crenças linguísticas e esforços para modificar ou influenciar as práticas através de algum tipo de intervenção, planejamento ou gestão. O primeiro aspecto consiste nas escolhas sociolinguísticas de um indivíduo e no padrão habitual de seleção de variedades que compõem o repertório linguístico de uma comunidade; o segundo diz respeito às ideologias e crenças que a comunidade tem em relação ao uso e às práticas linguísticas; e o terceiro, como o nome aponta, lida com esforços deliberados para manipular uma situação linguística.

No contexto universitário, tendo em vista as ações que envolvem línguas adicionais e seus possíveis desdobramentos, podemos entender tais aspectos da seguinte forma: as práticas podem dizer respeito às línguas em que a participação nas esferas de atividade que compõem a universidade acontece, como por exemplo alunos estrangeiros que não têm o português como primeira língua e dos quais é exigida a produção de textos em português acadêmico; as crenças podem nos apontar para os lugares que as línguas ocupam, de quais status elas desfrutam, quais são as mais ou menos desejadas no contexto acadêmico e quais seriam exigidas como pré-requisito para uma prova de admissão de mestrado, por exemplo; e quanto aos esforços para modificar ou influenciar uma situação linguística, podemos exemplificá-los com a escolha de quais línguas serão oferecidas em cursos de idiomas no âmbito universitário, quais testes de proficiência serão disponibilizados e aceitos pela universidade, que línguas de instrução serão utilizadas em determinados cursos de graduação ou pós-graduação e assim por diante.

Complementar às definições de Spolsky, Garcez e Schulz (2016) apontam que, ao ouvir o termo "políticas linguísticas", a maioria das pessoas pensa em leis, documentos oficiais e portarias, que de fato existem e compõem nossa sociedade e suas instituições; no entanto, políticas linguísticas podem também ser compreendidas como escolhas, práticas e decisões que tomamos com relação a línguas e suas ações consequentes. Nas palavras dos autores:

[...] onde há gente, há grupos de pessoas que falam línguas. Em cada um desses grupos, há decisões, tácitas ou explícitas, sobre como proceder, sobre o que é aceitável ou não, e por aí afora.

\footnotetext{
${ }^{6}$ Para Spolsky (2004, p.9) uma comunidade de fala é "qualquer grupo de pessoas que compartilham determinadas práticas e crenças de linguagem.”. De forma a aproximar esse conceito à realidade universitária, nos parece seguro afirmar que comunidades acadêmicas e comunidades de fala têm bastante em comum. Portanto, o termo comunidade neste artigo passa a ter acepção dupla: acadêmica e de fala.
} 
Vamos chamar essas escolhas - assim como as discussões que levam até elas e as ações que delas resultam - de políticas. (p.2) (GARCES, SHULZ, 2016) (grifos nossos)

Escolhas, discussões e ações sendo entendidas como políticas - tácitas ou explícitas, publicadas em documentos oficiais e/ou operantes em um ambiente - podem ser compreendidas e descritas também no contexto institucional da educação terciária. Nesse cenário, elas podem significar uma gama de escolhas feitas pelas pessoas que compõem a instituição no sentido de quais línguas promover, testar ou exigir, por exemplo, assim como através de quais instrumentos de avaliação linguísticas e utilizarão e quem estará à frente dessas ações. Também se fazem relevantes as noções de agência nas PL (GARCEZ, SCHULZ, 2016): “entre concepção, formulação e implementação, são diversos os caminhos e os atores envolvidos" (p.7), corroborando o caráter múltiplo e distinto dessas ações. Assim, neste artigo, ações que envolvem línguas e PL que acontecem no contexto acadêmico da UFRGS serão tomadas por sinônimos.

Para Dafouz e Smit (2014), "um número significativo e uma variedade de agentes tomam parte no planejamento, implementação e avaliação de políticas linguísticas em instituições de ensino superior no mundo todo.”(p.10). No contexto considerado neste artigo, as políticas descritas são promovidas e desempenhadas por diferentes instâncias e pessoas da universidade, assim como por entidades externas àinstituição, como organizações públicas e privadas que conciliam interesses com as IES e acabam implementando suas ações.

Segundo Bowe, Ball e Gold (1992), políticascomo documentos oficiais que norteiam práticas - o que é o caso de algumas das políticas operantes nas universidades-, detêm naturezas complexas; são concebidas, reconcebidas e gerenciadas de forma caótica e não linear, em contextos e com propósitos diferentes. De acordo com esses autores, os contextos pelos quais perpassam as políticas são três: o de influência, no qual elas são construídas; o de produção do texto e, portanto, da concepção da política; e o de prática, que é o contexto de implementação e que pode divergir da política primeiramente planejada. ${ }^{7}$

Nesse enquadramento, podemos compreender que as diversas ações descritas neste trabalho são cunhadas em diferentes momentos da história da instituição, revelando diferentes necessidades, demandas e vontades dos sujeitos que a compõem. Esses sujeitos engajaram em

\footnotetext{
${ }^{7}$ Importante ressaltar que não há uma ordem hierárquica entre os contextos. As políticas perpassam continua, constante e ciclicamente os três contextos.
} 
discussões (ou não) que resultaram em práticas e implementações de ações que envolvem línguas. E é a partir dessas práticas que podemos melhor perceber as PL de uma comunidade (SPOLSKY, 2004) ou, no caso deste trabalho, de uma instituição.

Assim, tendo aprofundado as noções de Internacionalização, Internacionalização em Casa e Políticas Linguísticas, passamos às ações operantes na UFRGS e sua relação com as línguas.

\section{Ações de internacionalização que envolvem línguas na UFRGS}

Para a investigação aqui descrita, foram selecionadas ações que ocorrem no âmbito da UFRGS, que envolvem línguas adicionais e que promovem ou culminam na internacionalização da universidade. As ações foram organizadas em três categorias: [1] ações de ensino, presencial e à distância, [2] ações de tradução e [3] testes de proficiência aplicados na universidade.

\subsection{Ações de Ensino}

\subsubsection{Escola de Desenvolvimento de Servidores da UFRGS}

O Programa de Idiomas da Escola de Desenvolvimento de Servidores da Universidade Federal do Rio Grande do Sul (EDUFRGS) tem por objetivo qualificar linguisticamente a atuação dos servidores da universidade através da oferta de ações de aperfeiçoamento que contemplam os seguintes idiomas: alemão, espanhol, francês, inglês e italiano. A EDUFRGS faz menção ao PDI da universidade, colocando a comunicação como ferramenta estratégica para o desenvolvimento institucional, e elemento chave para cumprir os objetivos de internacionalização do plano. ${ }^{8}$ Para mais informações, acesse: http://www.ufrgs.br/edufrgs.

\subsubsection{Programa Idiomas sem Fronteiras}

${ }^{8}$ Fonte: http://www.ufrgs.br/edufrgs/dqa/acoes-de-aperfeicoamento/programas/programa-de-idiomas. 
O Programa Idiomas sem Fronteiras, promovido pelo Ministério de Educação (MEC) e pela Coordenação de Aperfeiçoamento de Pessoal de Nível Superior (CAPES), é um programa nacional cujo principal objetivo é "promover ações em prol de uma política linguística para a internacionalização do Ensino Superior brasileiro, valorizando a formação especializada de professores de línguas estrangeiras" . O programa se constitui a partir de três módulos principais: aulas presenciais de línguas adicionais, em sua maioria na modalidade acadêmica; cursos onlinepara o ensino de conteúdo geral de línguas; e testagem de línguas, todos oferecidos gratuitamente e para toda a comunidade acadêmica (ABREU-E-LIMA et al., 2016).

As aulas presenciais são ministradas por graduandos ou graduados nos cursos de Licenciatura em Letras das IES brasileiras, oferecendo residência docente para professores em formação inicial ou continuada e capacitando esses profissionais para a internacionalização.

No contexto da UFRGS, tendo iniciado suas atividades em 2013, hoje o Núcleo de Língua do IsF na instituição oferece cursos de inglês, francês, japonês, português como língua adicional, espanhol e alemão, e oferece o teste de proficiência TOEFL ITP ${ }^{10}$. Para mais informações, acesse: $\underline{\text { http://isf.mec.gov.br/. }}$

\subsubsection{Assistentes de Ensino de Língua Inglesa Fulbright}

O Programa de Assistente de Ensino de Língua Inglesa (English Teaching Assistant ETA) para Projetos Institucionais é realizado pela CAPES em cooperação com a Fulbright, Comissão para o Intercâmbio Educacional entre os Estados Unidos da América e o Brasil. Traz norte-americanos de todas as regiões dos Estados Unidos ao Brasil para atuarem na universidade. A UFRGS vem aderindo ao programa e recebendo bolsistas desde 2014. Para mais informações, acesse: https://goo.gl/SdpRHQ.

\subsubsection{Programa Português para Estrangeiros}

${ }^{9}$ Fonte: https://goo.gl/Ez7MzV

${ }^{10}$ Fonte: $\underline{\text { htps://goo.gl/cASPsH }}$ 
O Programa de Português para Estrangeiros (PPE) é um programa de extensão, fundado em 1993, que promove o ensino de português como língua adicional. Oferece seminários de formação de professores, desenvolve pesquisa e elabora materiais didáticos na área de Português como Língua Adicional (PLA). Além disso, promove intercâmbios com instituições de ensino nacionais e internacionais. Dessa forma, o objetivo geral do PPE é promover a formação continuada de professores de PLA e contribuir para a expansão e o aprimoramento do ensino de PLA e da pesquisa na área. Alguns de seus objetivos específicos são oferecer cursos presenciais e a distância de PLA, literatura e cultura brasileira; aplicar o exame Celpe-Bras ${ }^{11}$; promover intercâmbio com universidades brasileiras e estrangeiras que atuam na área de PLA; e contribuir para a internacionalização da UFRGS. Para mais informações, acesse: http://www.ufrgs.br/ppe.

\subsubsection{Curso de Espanhol e Português para Intercâmbio}

O Curso de Espanhol e Português para Intercâmbio (CEPI) é resultado de esforços conjuntos da UFRGS, da Universidad Nacional de Córdoba e da Universidad Nacional de Entre Ríos, com o apoio do Ministério da Educação, Ciência e Tecnologia da Nação da Argentina. Através de uma ação político-acadêmica de integração regional, o CEPI aborda questões relacionadas à interculturalidade, mobilidade acadêmica, metodologia de ensino de línguas próximas, e ensino e aprendizagem de línguas em contextos virtuais. O curso tem por objetivo preparar o aluno para o intercâmbio, antecipando situações de inserção e adaptação ao contexto acadêmico e cultural em um ambiente virtual.

O Curso tem como público-alvo alunos participantes do programa Escala Estudiantil de intercâmbio acadêmico das universidades que compõem a Asociación de Universidades del Grupo Montevideo (AUGM). Para mais informações, acesse: https://www.ufrgs.br/cepi/.

\subsubsection{Curso Autoformativo de Português para Intercâmbio}

O Curso Autoformativo de Português para Intercâmbio (CAPI) é um curso de Português online ainda em construção. Sediado na UFRGS, o CAPI é promovido pela Secretaria de Educação a Distância (SEAD), em conjunto com a Produção Multimídia para a

\footnotetext{
${ }^{11} \mathrm{O}$ exame Celpe-Bras será descrito na subseção seguinte.
} 
Educação (NAPEAD) e com o PPE. Com propósitos similares aos do CEPI, descrito acima, o curso visa preparar alunos intercambistas para sua experiência em Porto Alegre e na UFRGS.

O site apresenta três módulos: vou fazer intercâmbio, vou morar em Porto Alegre e vou estudar na UFRGS. Desses módulos, apenas o primeiro apresenta tarefas concluídas; os restantes se encontram em construção. Para mais informações, acesse: https://www.ufrgs.br/capi/index.php?r=site/index.

\subsubsection{Instituto Confúcio}

O Instituto Confúcio é uma instituição chinesa sem fins lucrativos que promove ensino da língua e da cultura chinesas para a comunidade acadêmica da UFRGS e para o público em geral. Ele tem por missões ensinar a língua e a cultura chinesas, promover a amizade entre os povos, a diversificação cultural e a paz entre os países. Também, entre seus objetivos, o instituto busca despertar a curiosidade das pessoas a respeito da China e expandir a área de pesquisa de chinês e português para estrangeiros.

O Instituto foi fundado pela cooperação entre a UFRGS e a Universidade de Comunicação da China, com o suporte pedagógico, cultural e financeiro da sede matriz do Instituto Confúcio, localizada em Pequim. Dentro das ações promovidas pelo instituto, destacam-se o curso de língua chinesa e os exames de proficiência em mandarim (HSK e HSKK). Para mais informações, acesse: https://www.ufrgs.br/confucio/

\subsection{Ação de tradução}

\subsubsection{Empresa Júnior de Tradução e Revisão do Bacharelado em Letras}

Fundada em 2018, a Empresa Júnior Textualiza realiza trabalhos de revisão e tradução para as seguintes línguas adicionais: alemão, espanhol, francês, inglês, italiano e japonês. Seu corpo profissional é composto de alunos do curso de Bacharelado em Letras, que prestam serviços de tradução à comunidade acadêmica a ao público em geral. A empresa procura ajudar na capacitação e desenvolvimento pessoal e profissional dos estudantes, futuros tradutores e revisores. Tem por missão "proporcionar, de forma colaborativa, experiências profissionais e de autogestão aos membros, de forma a cultivar um espaço de reflexão e 
debate" sobre o futuro desses empreendedores como profissionais do texto. Para mais informações, acesse: https://www.facebook.com/pg/TextualizaJr/about/.

\subsection{Testes de proficiência}

\subsubsection{Comissão de Avaliação de Proficiência de Leitura em Línguas Estrangeiras}

A Comissão de Avaliação de Proficiência de Leitura em Línguas Estrangeiras (CAPLLE) é uma comissão vinculada ao Departamento de Línguas Modernas do Instituto de Letras. Ela tem por objetivo oferecer provas de proficiência de leitura em língua estrangeira para candidatos a cursos de pós-graduação (mestrado e doutorado), alunos regularmente matriculados em Programas de Pós-Graduação (PPG) da UFRGS e para a comunidade em geral. Além disso, a CAPLLE também avalia a possibilidade de equivalência de outras provas de proficiência como substitutivas às provas da CAPLLE, nesse contexto exclusivamente para alunos dos PPG da UFRGS ${ }^{12}$, que têm por condição de titulação a proficiência em língua estrangeira atestada.

A comissão é composta por professores de alemão, espanhol, francês, italiano e inglês do IL, que elaboram e corrigem as provas. O candidato pode optar por qualquer uma das línguas elencadas como opções no curso em que está matriculado. Alunos surdos, representados pelos seus PPGs, podem solicitar prova de leitura em PLA, e alunos estrangeiros são encaminhados ao exame Celpe-Bras. Para mais informações, acesse: http://www.ufrgs.br/caplle/.

\subsubsection{Certificado de Proficiência em Língua Portuguesa para Estrangeiros}

O Certificado de Proficiência em Língua Portuguesa para Estrangeiros (Celpe-Bras) é o único teste de proficiência em português como língua adicional reconhecido pelo governo brasileiro. Desenvolvido pelo Ministério de Educação e Cultura, e com apoio do Ministério de Relações Exteriores, as provas são realizadas em postos aplicadores, IES brasileiras e no exterior. Internacionalmente, o certificado é aceito em empresas e instituições de ensino como comprovação de competência na língua portuguesa. No Brasil, é comumente exigido

\footnotetext{
${ }^{12}$ Para conferir o sistema de equivalência, acesse o site http://www.ufrgs.br/caplle/equivalencia.html
} 
pelas universidades para ingresso em cursos de graduação e em programas de pós-graduação, assim como para validação de diplomas de profissionais estrangeiros que têm por intenção trabalhar no país.

Na UFRGS, o PPE é responsável pela aplicação do Celpe-Bras. Para mais informações, acesse: http://portal.inep.gov.br/acoes-internacionais/celpe-bras.

\subsubsection{Hanyu Shuiping Kaoshi}

Os exames oficiais Hanyu Shuiping Kaoshi (HSK e HSKK) são testes de proficiência de língua chinesa reconhecidos oficialmente pelo governo chinês, pelas universidades e empresas do país. O primeiro teste mede a habilidade dos aplicantes em se comunicar na língua chinesa em três contextos: o cotidiano, o acadêmico e o profissional e apresenta três seções: de compreensão auditiva, leitura e escrita. Já o HSKK é um teste que mede exclusivamente a compreensão auditiva e fala dos estudantes de língua chinesa. O Instituto Confúcio na UFRGS é responsável pelas inscrições e aplicações dessas provas. Para mais informações, acesse: https://www.ufrgs.br/confucio/hsk_e_hskk/.

\subsubsection{Test of English as a Foreign Language -Institutional Testing Program}

O Test of English as a Foreign Language (TOEFL) Institutional Testing Program $(\text { ITP })^{13}$ é um teste de proficiência em língua inglesa amplamente aplicado pelas IES brasileiras nos últimos anos (ABREU-E-LIMA et al., 2016). Em formato de papel e todo em múltipla escolha, visa avaliar a proficiência acadêmica de falantes não nativos do inglês. $O$ teste é composto por três seções: compreensão auditiva, estrutura e expressão escrita e leitura.

A UFRGS é Centro Aplicador credenciado pela MasterTest para aplicar provas de proficiência TOEFL ITP desde 2013 (WELP, FONTES, SARMENTO, 2016), através de seu NucLi, para alguns editais de mobilidade e para nivelamento dos cursos presenciais do IsF. Para mais informações, acesse: https://www.ets.org/toefl_itp..

\subsubsection{Certificado de Español Lengua y Uso}

\footnotetext{
${ }^{13}$ Teste de Inglês como uma Língua Estrangeira (TOEFL) Programa de Testagem Institucional (ITP), em Português (traduções nossas).
} 
O Certificado de Español Lengua y Uso (CELU) é um teste de proficiência em língua espanhola reconhecido pelo Ministério de Educação da República da Argentina. Ele avalia a competência linguística comunicativa oral e escrita do espanhol como língua adicional. $\mathrm{O}$ Setor de Espanhol do Instituto de Letras se responsabiliza pelas inscrições e aplicações da prova. Para mais informações, acesse: https://www.celu.edu.ar/.

\section{Discussão}

As IES brasileiras são, de fato, universos de ações e de políticas linguísticas relacionadas à internacionalização. Diferentes grupos de pessoas, em diferentes momentos e com diferentes propósitos, têm se engajado em esforços deliberados para possibilitar ações institucionais que envolvem línguas adicionais e que têm por objetivo ou por resultado a internacionalização das universidades. Na UFRGS, é observável que, mesmo antes das discussões sobre a internacionalização das IES brasileiras se avolumarem, a instituição já desempenhava ações que promoviam sua internacionalização. Nesse contexto, entre as ações descritas na seção anterior, alguns pontos merecem atenção.

É natural e notável o papel que o Instituto de Letras, seus professores, departamentos e programas, ocupam no processo de internacionalização da UFRGS, por centralizar ou ser a base da maioria das ações descritas que envolvem ensino presencial de línguas adicionais. Percebe-se uma forte presença de formação de profissionais, seja de professores nos programas IsF ou PPE, seja de tradutores na Empresa Júnior de tradução. Parece haver sempre um espaço destinado a essas discussões e eventos de formação, até mesmo com a presença dos ETAs, que vêm colaborar com o ensino de línguas e formar professores de línguas qualificados.

Explicitamente para fins de internacionalização, tivemos descritos os cursos oferecidos pelo CAPI e o CEPI, cursos online de Português como Língua Adicional, voltados especificamente para a mobilidade acadêmica. Essa mesma natureza explícita pode ser encontrada nas ações do IsF, PPE, do programa ETAs e do Instituto Confúcio, que fazem menções ao suporte à internacionalização, que integram o ensino com dimensões internacionais e interculturais, e alinhando-se às definições de internacionalização de Knight (2008) e ao PDI da UFRGS. 
No que concerne testagem de línguas, a CAPLLE tem uma preocupação específica com a pós-graduação, oferecendo testes de proficiência em leitura em língua adicional para alunos ingressantes nos PPGs UFRGS, o que revela uma política linguística da universidade: para ingressar em um PPG UFRGS, o candidato deve comprovar sua habilidade de compreender textos produzidos em determinadas línguas. A Comissão também direciona alunos estrangeiros para o Celpe-Bras, outra iniciativa de destaque para a internacionalização que funciona como único teste de proficiência nacionalmente reconhecido pelo governo brasileiro. Além desses, as provas HSK e HSKK do governo chinês são aplicadas pelo Instituto Confúcio, revelando parcerias entre a UFRGS e IES chinesas. O mesmo acontece com a prova CELU, que representa uma parceria com universidades argentinas. O TOEFL ITP, em especial, amplamente à disposição dos alunos, docentes e técnicos da UFRGS, serve como porta de entrada para oportunidades de mobilidade. Dessa forma, as diversas línguas testadas na UFRGS acabam por oferecer possibilidade de interlocução com o conhecimento científico e de mundo disponível produzido nessas línguas. Essas escolhas, conforme explicado por Garcez e Shulz (2016), evidenciam uma política linguística voltada ao multilinguismo.

Destaca-se também a ação que envolve tradução, a Empresa Júnior Textualiza que começa a prestar seus serviços à comunidade. A iniciativa emerge de uma demanda linguística percebida, e, a partir dela, a oportunidade de empreender e servir à comunidade, oferecendo, dessa forma, a possibilidade de ampliação da visibilidade da produção científica da UFRGS.

Dessa forma, pode-se perceber como a internacionalização se dá na UFRGS: de forma caótica e não-linear, como nas políticas descritas por Bowe, Ball e Gold (1992), fruto de debates recentes e frequentes. As iniciativas nesse sentido atendem a demandas internacionais, e ao mesmo tempo investem localmente, promovendo ações de Internacionalização em Casa. Estas últimas têm o impacto de contribuir, cada vez mais, com o estabelecimento de contextos multilíngues que melhor preparem os alunos da universidade para um mundo conectado, constituindo uma comunidade acadêmica ainda mais preparada para lidar com a pluralidade, em consonância assim com o conceito de internacionalização de Knight (2008). Como resultado, alunos, professores e servidores se capacitam e desenvolvem competências e habilidades internacionais e interculturais, linguísticas e pessoais, formando uma comunidade mais qualificada para enfrentar os desafios encontrados internacionalmente 
e também para receber visitantes internacionais em um ambiente mais acolhedor linguisticamente.

\section{Considerações finais}

Por fim, vale mencionar que os objetivos $\mathrm{e}$ as responsabilidades da internacionalização envolvem buscar não só a qualidade do ensino superior, mas também partilhar do comprometimento com pautas globais de interesse comum através de oportunidades de interlocução internacional. Destaca-se aqui uma perspectiva da internacionalização da UFRGS como um processo em contínua construção voltado para a ampliação da participação no debate acadêmico internacional, na qualificação daqueles que vivem o dia a dia da universidade, e que estão envolvidos nas ações aqui descritas de uma forma ou de outra, e na visibilidade da produção científica local. Assim, através de ações voltadas para a internacionalização, alunos, professores, pesquisadores e técnicos da UFRGS podem, juntos, se tornar catalisadores de mudançasem suas áreas de conhecimento e, de fato, cumprir com os compromissos firmados com a sociedade.

\section{REFERÊNCIAS}

ABREU-E-LIMA, Denise et al. O Programa Inglês sem Fronteiras e a Política de Incentivo à Internacionalização do Ensino Superior Brasileiro. In: SARMENTO, Simone et al. (Org.) Do Inglês sem Fronteiras ao Idiomas sem Fronteiras: A construção de uma política linguística para a internacionalização. Belo Horizonte: Editora UFMG, 2016, p.19-46.

ALPERIN, Juan Pablo. Brazil's exception to the world-class university movement. In: WILLIAMS, James (Org.) Quality in Higher Education. Londres: Routledge, 2013, v. 19, n. 2, p.158-172.

BRITISH COUNCIL. Universidades para o Mundo: Desafios e Oportunidades para a Internacionalização. São Paulo: British Council, 2018.

BOWE, Richard; BALL, Stephen; GOLD, Anne. The Policy process and the processes of policy. In: Reforming education \& changing schools: case studies in policy sociology. Londres: Routledge, 1992, p. 6-23.

BAUMVOL, Laura; SARMENTO, Simone. Languages and Internationalization of Higher Education: Analysis of FAUBAI Conferences. Faubai.org. Disponível em:

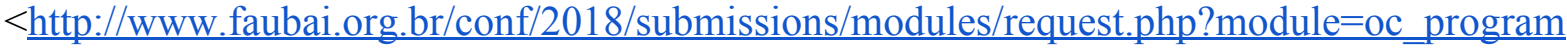
\&action=view.php\&id=47\&file=1/47.pdf\&c=1> Acesso em 05 jul. de 2018. 
DAFOUZ, Emma, SMIT, Ute. Towards a Dynamic Conceptual Framework for English-Medium Education in Multilingual University Settings. In: Applied Linguistics. Oxford: Oxford University Press, 2014, p. 1-20.

DOWLE, Martin. Internacionalizar em Busca de Excelência.In: BRITISH COUNCIL (Org.). Universidades Para o Mundo: Desafios e Oportunidades para a Internacionalização. São Paulo: British Council, 2018, p. 6-7.

GARCEZ, Pedro de M.; SCHULZ, Lia. ReVEL na Escola: do que tratam as políticas linguísticas? Porto Alegre: ReVEL, v. 14, n. 26, 2016, p.1-19.

KNIGHT, Jane. Higher Education in Turmoil: The changing World of Internationalization. Rotterdam: SensePublishers, 2008.

NICOLAIDES, Christine.; TILIO, Rogério. Políticas de ensino e aprendizagem de línguas adicionais No contexto brasileiro: o caminho trilhado pela ALAB. Em: NICOLAIDES, C.; TILIO, R.; SILVA, K.; ROCHA, C. (Orgs.) Politica e Politicas Linguísticas. Campinas, SP: Pontes Editores, 2013.

SANTOS, Solange Maria. O desempenho das universidades brasileiras nos rankings internacionais: áreas de destaque da produção científica brasileira. Tese (Doutorado) - Escola de Comunicações e Artes, Universidade de São Paulo, São Paulo. 2015.

SARMENTO, Simone. Internationalization and Additional Languages. Porto Alegre: The English Muffin Newsletter. Disponível em: $<$ https://mailchi.mp/57a9c8c9844b/internationalization-and-additional-languages-by-simone-

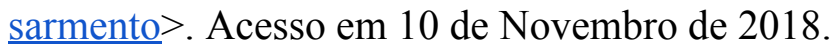

SPOSLKY, Bernard. Language Policy. United Kingdom: Cambridge University Press, 2004

TEEKENS, Hanneke. Internationalisation at home - Crossing other borders. University World News, n. 276, 2013.Disponível em<https://goo.gl/QnVBFe $>$

UFRGS. Universidade Federal do Rio Grande do Sul. Plano de Desenvolvimento Institucional: PDI 2016-2026: Construa o futuro da UFRGS. Porto Alegre: UFRGS. Disponível em: < http://www.ufrgs.br/pdi/PDI 2016a2026_UFRGS.pdf $>$ Acesso em: 07 de fev. de 2018.

WELP, FONTES, SARMENTO. O Programa Idiomas sem Fronteiras na Universidade Federal do Rio Grande do Sul. In: SARMENTO et al. (Org.) Do Inglês sem Fronteiras ao Idiomas sem Fronteiras: A construção de uma política linguística para a internacionalização. Belo Horizonte: Editora UFMG, 2016, p. 125-147.

Recebido em 17/03/2019. Aceito em 02/07/2019. 